\title{
Olanzapine May Inhibit Colonic Motility Associated with the 5-HT Receptor and Myosin Light Chain Kinase
}

\author{
Jiarui Zhang ${ }^{1 *}$,Ying Qiao ${ }^{2 *}$, Jingjing Le ${ }^{3}$, Daliang Sun ${ }^{\bowtie}$, Yangtai Guan ${ }^{4}$, and Zezhi $\mathrm{Li}^{4} \bowtie$ \\ ${ }^{1}$ Tianjin Mental Health Center, Tianjin, China \\ ${ }^{2}$ Shanghai Mental Health Center, Shanghai Jiao Tong University School of Medicine, Shanghai, China \\ ${ }^{3}$ Department of Integrated Traditional Chinese Medicine and Western Medicine, Huashan Hospital, Fudan University, Shanghai, China \\ ${ }^{4}$ Department of Neurology, Ren Ji Hospital, School of Medicine, Shanghai Jiao Tong University, Shanghai, China
}

Objective To study whether the effects of olanzapine on gastrointestinal motility is related to the serotonin antagonism and myosin light chain kinase.

Methods Male Sprague-Dawley rats were randomly divided into four groups. Olanzapine gavage was performed for each treatment group during the course of 30 continuous days, while the same volume of saline was given to the rats in the control group. Defecation of the rats was observed on days 7 and 30 after olanzapine gavage. The effects of olanzapine on contraction of colonic smooth muscles were observed in ex vivo experiments. A Western blot was used to evaluate expression levels of the serotonin transporter (SERT) and MLCK in colon segments of the rats.

Results Compared to the control group, 5-160 $\mu \mathrm{M}$ of olanzapine could inhibit dose-dependently the contraction of colonic smooth muscle ex vivo experiments. The maximum smooth muscle contraction effects of 5-HT and acetylcholine significantly decreased after treatment with $40-160 \mu \mathrm{M}$ of olanzapine. Constipation was found in the olanzapine-treated rats on day 7 and have sustained day 30 after gavage. Expression of MLCK in olanzapine-treated rats was significantly decreased, whereas the expression of SERT significantly increased on the day 7 , then significantly decreased on the day 30 after olanzapine gavage.

Conclusion SERT and MLCK may involve in the inhibition of colonic contraction induced by olanzapine.

Psychiatry Investig 2016;13(2):232-238

Key Words Antipsychotic agents, Intestinal motility, Serotonin system, Myosin light chain kinase.

\section{INTRODUCTION}

Olanzapine is an atypical antipsychotic agent that is used to effectively treat symptomatic and asymptomatic schizophrenia. However, several adverse effects including tiredness,

Received: February 9, 2015 Revised: June 21, 2015

Accepted: August 12, 2015 Available online: January 8, 2016

$\triangle$ Correspondence: Daliang Sun, MD, PhD

Tianjin Mental Health Center, 13 Liulin Road, Tianjin 300222, China Tel: +86-15122889423, Fax: +862288188818, E-mail: daliangsun@yeah.net

$\triangle$ Correspondence: Zezhi Li, MD, PhD

Department of Neurology, Ren Ji Hospital, School of Medicine, Shanghai Jiao Tong University, 1630 Dongfang Road, Shanghai 200127, China

Tel: +86-13564648631, Fax: +86-2158394262

E-mail: lizezhi1981@aliyun.com

$\triangle$ Correspondence: Yangtai Guan, MD, PhD

Department of Neurology, Ren Ji Hospital, School of Medicine, Shanghai Jiao Tong University, 1630 Dongfang Road, Shanghai 200127, China

Tel: +86-13386271865, Fax: +86-2158394262, E-mail: yangtaiguan@sina.com

*These authors contributed equally to this work.

(c) This is an Open Access article distributed under the terms of the Creative Commons Attribution Non-Commercial License (http://creativecommons.org/licenses/bync/3.0) which permits unrestricted non-commercial use, distribution, and reproduction in any medium, provided the original work is properly cited. weight increase, and constipation have been reported in clinical practice. Compared to other antipsychotic agents, the incidence rate of constipation is $9-11 \%$ higher in patients treated with olanzapine. ${ }^{1}$ Additionally, a dose-dependent increase in constipation instances has also been reported. ${ }^{2,3}$ Constipation induced by olanzapine could aggravate to the point of lifethreatening complications including: intestinal obstruction, ischemia, and even perforation if no effective treatment has been administered. ${ }^{4}$ Previous studies suggested that antagonism of the peripheral cholinergic $M$ receptor could be involved in constipation induced by olanzapine. In vivo and in vitro experiments have shown that although olanzapine has a high affinity to the M receptor, the antagonistic effects of olanzapine on M receptor are relatively low. ${ }^{5,6}$ Therefore, it is hypothesized that there are other mechanisms involved in the high incidence of constipation induced by olanzapine.

Olanzapine may antagonize multiple receptors. Previous studies have shown that olanzapine has affinities for dopamine receptors $\left(\mathrm{D}_{1}-\mathrm{D}_{5}\right), 5-\mathrm{HT}$ receptors $\left(5-\mathrm{HT}_{1}, 5-\mathrm{HT}_{2}, 5-\mathrm{HT}_{3}\right.$, and 
5- $\mathrm{HT}_{6}$ ), $\alpha$-adrenergic receptor, histamine $\mathrm{H}_{1}$ receptor, and muscarinic receptors $\left(\mathrm{M}_{1}-\mathrm{M}_{5}\right){ }^{1,5,7}$ As an important neurotransmitter, 5-HT could participate in regulating the sensory, motility, and secretion of the digestive system and has been considered as a mediator for gut-brain connection. ${ }^{8}$ About $95 \%$ of the 5-HT in the human body is located in the gastrointestinal tract. For most of people, 5-HT is synthesized and secreted by enterochromaffin cells into gastrointestinal lumens and the blood. ${ }^{9}$ Released 5-HT could then combine into different kinds of receptors $\left(5 \mathrm{HT}_{1}-5 \mathrm{HT}_{7}\right.$ receptors) and exert different effects. 5 -HT is then transferred back to cells by serotonin transporter (SERT) and made inactive. Previous studies have demonstrated that 5 -HT receptor subtypes that could potentially affect the intestinal motilities include $5-\mathrm{HT}_{3}$, $5-\mathrm{HT}_{4}$, and $5 \mathrm{HT}_{7}$ receptors, ${ }^{10}$ while olanzapine can distinctly antagonize $5-\mathrm{HT}_{3}$ receptor. ${ }^{11} 5-\mathrm{HT}_{3}$ receptor are expressed mainly in gastrointestinal smooth muscle tissue, which could regulate the contraction of the smooth muscles and the secretion of gastric fluid. ${ }^{12}$ Guinea pig experiments showed that olanzapine could block the contraction of ex vivo ileum induced by $5-\mathrm{HT}_{3}$ receptor agonists, suggesting that the antagonistic effects of olanzapine on the serotonin system should not be neglected. ${ }^{11}$ SERT plays an important role in terminating the effects of 5-HT as a neurotransmitter and maintaining the homeostasis of neurotransmitters. ${ }^{10}$ Previous studies have shown that SERT is involved in the development and progression of irritable bowel syndrome (IBS). ${ }^{13,14}$ This evidence shows that the antagonism effect of olanzapine on serotonin as well as SERT both play important roles in intestinal motility dysfunctions as well as visceral paraesthesia. ${ }^{10,15}$

One the other hand, Myosin light chain kinase (MLCK) is an important protein involved in the inositol triphosphate and calmodulin (CaM) signal transduction pathway. Previous studies have shown that MLCK could promote the phosphorylation of myosin light chains (20 KD), which interact with actin to induce the contraction of intestinal smooth muscles. This suggests a close association between MLCK and gastrointestinal motility. ${ }^{16,17}$ Several animal experiments also show that MLCK expression is decreased within the gastrointestinal mucosa of diabetic rats with gastrointestinal dysfunctions. ${ }^{18}$ Therefore, the aim of this study was to investigate the potential role of serotonin antagonist and MLCK in olanzapine-induced constipation. The present study examined the effect of olanzapine on intestinal motility induced by $5-\mathrm{HT}$ and MLCK in vivo.

\section{METHODS}

\section{Animals}

Forty male Sprague-Dawley (SD) rats (body weight of 180-
220 g, Vital River Laboratory Animal Technology Co. Ltd., Beijing, China) were randomly divided into 4 groups of 10 and named: control group, low dose (olanzapine) group (0.5 $\mathrm{mg} / \mathrm{kg} /$ day), moderate dose group ( $2 \mathrm{mg} / \mathrm{kg} /$ day), and high dose group ( $8 \mathrm{mg} / \mathrm{kg} /$ day). Procedures for the animals were performed according to the "Guide for the Care and Use of Laboratory Animals" (NIH Publication No.80-23) issued by National Institute of Health (NIH). Gavage of olanzapine was performed at 7 oclock every morning for the treatment groups, while gavage of normal saline was performed for the control group at the same time. The overall volume of gavage was $2 \mathrm{~mL}$ every day. All the animals were treated for 30 continuous days.

\section{Reagents}

Olanzapine crude ingredient (light yellow powder, purity of 98\%) was purchased from Yibang Biomedical Technology Co., Ltd (Guangzhou, China). The crude ingredient was dissolved in an appropriate volume of $5 \%$ glacial acetic acid (V/ $\mathrm{V})$, and then $\mathrm{pH}$ adjusted to 5.5 with $\mathrm{NaOH}$. Klein's solution (mmol/L) was prepared by mixing $\mathrm{NaCl}$ (114.0), $\mathrm{KCl}$ (4.7), $\mathrm{MgCl}_{2}$ (1.2), $\mathrm{CaCl}_{2}$ (2.5), $\mathrm{H}_{2} \mathrm{PO}^{-1}$ (1.8), glucose (11.5), and $\mathrm{NaHCO}_{3}$ (18.0) before being $\mathrm{pH}$ adjusted to $7.4 \pm 0.5$.

\section{Experimental design}

\section{Preparation of ex vivo colonic smooth muscle and measurement of the tension ${ }^{19}$}

The rats were sacrificed and their colons were collected. A segment of colon about 1-2 cm of length was quickly obtained and preserved in an ice-bath for 5-8 hours with ventilation. One end of the colon segment was fixed on the hook of an Lshaped tube, while the other end of the colon segment was hung on the hook. The tension of the colon segment was adjusted to ensure the preload of the smooth muscle was $1.0 \mathrm{~g}$ before contraction. Then a recorder was connected through a tension sensor and the muscle tension curve was recorded for 50 minutes.

\section{Dose-response curve of olanzapine}

After the contraction of the colonic smooth muscles stabilized, different doses $(5,10,20,40,80$, and $160 \mu \mathrm{M})$ of olanzapine were added, and then changes in smooth muscle contraction were examined. For each dose of olanzapine, the tension curve was recorded for at least one minute. All the drug administration were completed within 20 minutes.

Influences of olanzapine on the colonic motility-promoting effects of Ach and 5-HT

After the contraction of the colonic smooth muscles stabilized, $40 \mu \mathrm{M}$ of olanzapine was added and incubated for 5 
minutes. Then different doses $(5,10,20,40,80$, and $160 \mu \mathrm{M})$ of acetylcholine (ACh) were added and changes in the smooth muscle contraction were examined. For each dose of olanzapine, the tension curve was recorded for at least one minute. All of the drug administration were completed within 20 minutes, and the dose-response curve of ACh was obtained. The colon segment was changed, and then a dose-response curve of 5-HT was obtained using the same method.

\section{Expression of SERT and MLCK}

Five rats from each group were sacrificed on day 7 and day 30 , respectively. Colons of the rats were obtained and the expression of SERT was measured. In addition, MLCK expression was also measured on the day 30 by Western blot. The total proteins were extracted using kits (Qiagen), and then separated by electrophoresis (JM-250, Dalian, China) with a protein loading quantity of $50 \mu \mathrm{g}$. After electrophoresis, a semi-dry transfer (ST-I, Dalian, China) was used to transfer proteins for 1.5 hours. Then the PVDF membrane (containing protein bands) was incubated with MLCK antibody (1:1000) (Abcam, Hong Kong) overnight. A multispectral imaging system (UVP, Cambridge, UK) was used for the determination and quantification of the bands. Quantification of SERT protein in the colonic tissues was performed using a similar method as in the quantification of MLCK protein, except that the antibody used was SERT antibody (1:1000) (Abcam, Hong Kong). The mean value of each band was calculated as follows: value of the target protein=gray-scale value of the target protein/gray scale value of the internal reference protein.

\section{Defecation of the rats ${ }^{20}$}

The amount of the feces from the rats were recorded before gavage every day. The number was recorded as the number of feces after the last gavage but before the present gavage. For the rats with diarrhea, a smudge was considered to be one feces. The number of feces within 8 hours after the gavage at 7 oclock was then recorded, and the frequency of defection was calculated as follows: number of feces/8 (hours)/rat number. Fresh feces from the rats were weighed as the wet weight, and the weight after the feces were dried was recorded as the dry weight. Water content in the feces was calculated as follows: (wet weight-dry weight)/wet weight.

\section{Statistical analysis}

SPSS 17.0 software was used for the statistical analysis. All the quantitative data were described as means \pm standard divisions $(\bar{\chi} \pm s)$. One-way analysis of variance was used for the comparison of the means among different groups, while LSD test was used for the pairwise comparisons. $\mathrm{p}<0.05$ was considered statistically significant.

\section{RESULTS}

\section{Effects of olanzapine on the contraction of the smooth muscles in ex vivo colon}

Compared with the control group, the contraction of smooth muscles in the ex vivo colon tissues was significantly inhibited by $5-160 \mu \mathrm{M}$ of olanzapine, and the effect was dose dependent (Figure 1A). The $\mathrm{EC}_{50}$ of olanzapine was $40 \mu \mathrm{M}$ (Figure 1B). After incubation with $160 \mu \mathrm{M}$ of olanzapine, the con-
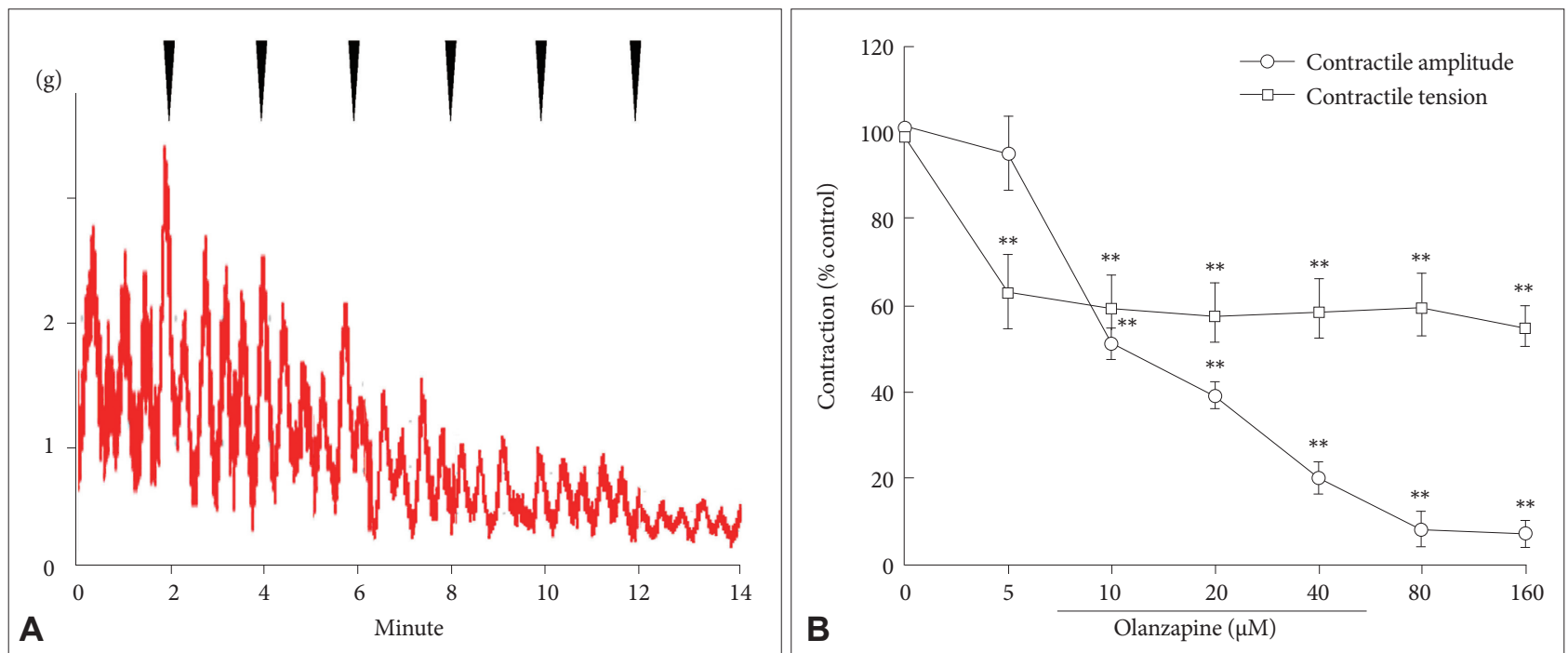

Figure 1. Effects of olanzapine on the contraction of smooth muscles in the ex vivo colons. A: Meant the contraction of smooth muscles weaken accompanying with olanzapine effect on the ex vivo colons. B: Meant different doses of olanzapine added to the smooth muscle was indicated by the arrows above. The x-axis means the time of olanzapine injection. The stable recorder for smooth muscle without olanzapine was as comparison. Data were expressed as mean \pm standard division, $\mathrm{N}=6$. The value in the control group was considered as $100 \% .{ }^{* *} \mathrm{p}<0.01$. 
traction amplitude of the colonic smooth muscles decreased from $100.0 \%$ ( \pm 13.4$)$ to $15.4 \%$ ( \pm 2.6$)$ ( $\mathrm{p}<0.01 ; \mathrm{n}=6$ tissues), and the contractile tension decreased from $100.0 \%( \pm 5.6)$ to $70.1 \%( \pm 4.8)(\mathrm{p}<0.01 ; \mathrm{n}=6$ tissues $)$ (Figure 1B).

\section{Influences of olanzapine on the colonic motility- promoting effects of ACh and 5-HT}

As shown in Figure 2, after incubation with $40 \mu \mathrm{M}$ of olanzapine, the maximal effects of 5-HT and ACh in improving the contraction of the smooth muscles of the colon decreased significantly $(\mathrm{p}<0.01)$. In detail, the contraction of the smooth muscles in the colon treated with 5 -HT decreased from $371.2 \%$ ( \pm 22.8$)$ to $237.1 \%( \pm 17.9)$ (Figure $2 \mathrm{~A})$, while the contraction of the smooth muscles in the colon treated with Ach decreased from $263.2 \%$ ( \pm 17.6$)$ to $155.1 \%$ ( \pm 11.4 ) (Figure $2 \mathrm{~B}$ ). Both the dose-response curves of 5-HT and ACh shifted significantly upward.

\section{Effects of olanzapine on defecation of the rats}

In contrast to the control group, constipation was found in the rats from each treatment group one week after the gavage of olanzapine. The presentations included a significant decrease in the number of feces, defecation frequency, and water content $(p<0.01)$. The rats in each treatment group were found to have constipation by day 30 (Table 1).

\section{Effects of olanzapine on SERT expression}

As shown in the Figure 3, the SERT level increased on day 7 after olanzapine gavage. The SERT level in the high dose group was $210.2 \%( \pm 19.3)$, which was significantly higher than the level in the control group $100.0 \%( \pm 11.2)(\mathrm{p}<0.01)$. In contrast, SERT level in the treatment groups was lower than the levels in the control group on the day 30, after olanzapine gavage. The SERT level in the high dose group was $61.2 \%$ $( \pm 5.5)$, which were significantly lower than the level in the control group $100.0 \%( \pm 9.8)(\mathrm{p}<0.01)$.
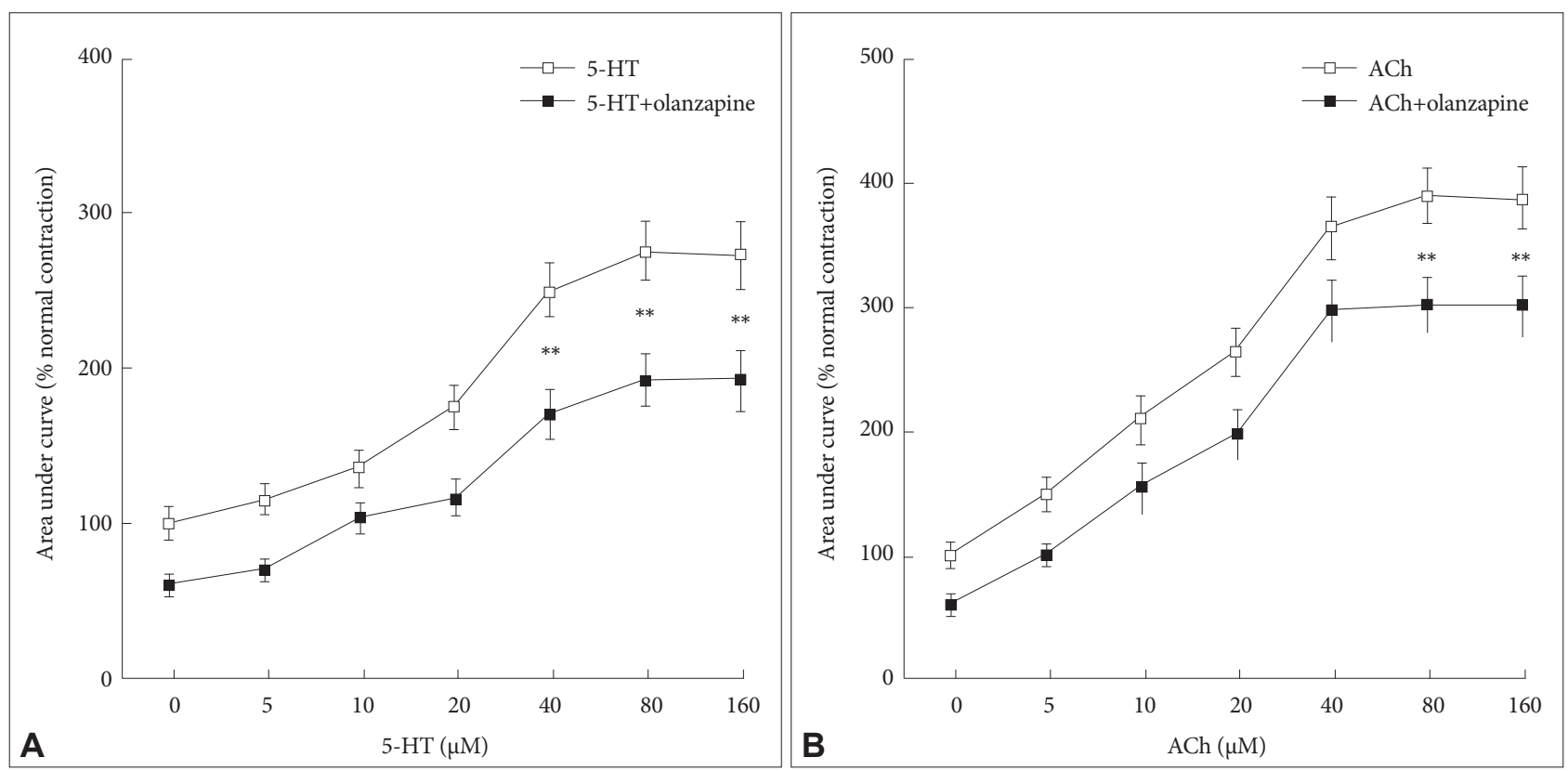

Figure 2. Influences of olanzapine on the colonic motility-promoting effects of 5-HT (A) and ACh (B). All the data were expressed as means \pm standard divisions, $\mathrm{N}=6$. The value in the control group was considered as $100 \%{ }^{* *} \mathrm{p}<0.01 .5-\mathrm{HT}$ : serotonin, ACh: acetylcholine.

Table 1. Effects of olanzapine on defecation of the rats

\begin{tabular}{|c|c|c|c|c|c|c|}
\hline & \multicolumn{3}{|c|}{ Day 7} & \multicolumn{3}{|c|}{ Day 30} \\
\hline & Feces number & Water content & $\begin{array}{l}\text { Defecation } \\
\text { frequency }\end{array}$ & Feces number & Water content & $\begin{array}{l}\text { Defecation } \\
\text { frequency }\end{array}$ \\
\hline Control group & $100 \pm 21$ & $100 \pm 19$ & $100 \pm 16$ & $100 \pm 17$ & $100 \pm 13$ & $100 \pm 20$ \\
\hline Low dose group & $32 \pm 2^{* *}$ & $63 \pm 11^{* *}$ & $33 \pm 2 * *$ & $29 \pm 3^{* *}$ & $55 \pm 7^{* *}$ & $30 \pm 4^{* *}$ \\
\hline Moderate dose group & $37 \pm 3^{* *}$ & $61 \pm 8^{* *}$ & $31 \pm 4^{* *}$ & $35 \pm 4^{* *}$ & $50 \pm 4^{* *}$ & $28 \pm 6^{* *}$ \\
\hline High dose group & $33 \pm 6^{* *}$ & $68 \pm 9^{* *}$ & $35 \pm 6^{* *}$ & $31 \pm 4^{* *}$ & $60 \pm 1^{* *}$ & $29 \pm 7^{* *}$ \\
\hline
\end{tabular}

All the data were expressed as mean \pm standard division, $\mathrm{N}=6$. The value in the control group was considered as $100 \%\left({ }^{* *} \mathrm{p}<0.01\right)$ 


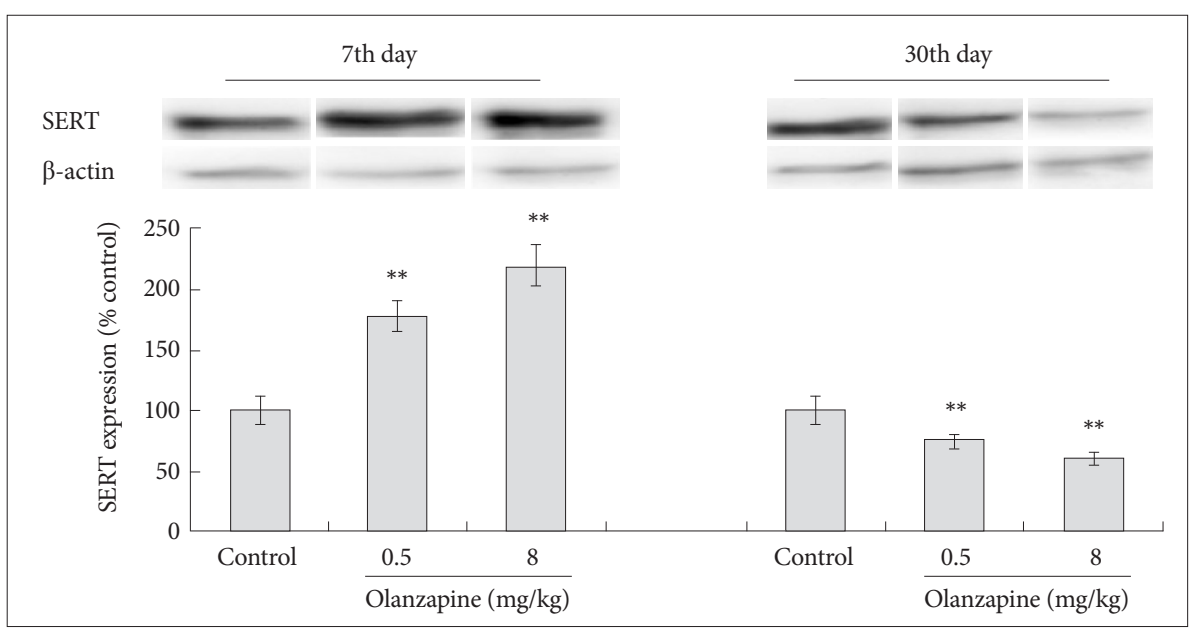

Figure 3. Effects of olanzapine on SERT expression. All these data were expressed as means \pm standard divisions, $\mathrm{N}=4$. The value in the control group was considered as $100 \%$. ${ }^{* *} p<0.01$. $\beta$-actin was used as the internal reference. SERT: serotonin transporter, MLCK: myosin light chain kinase.

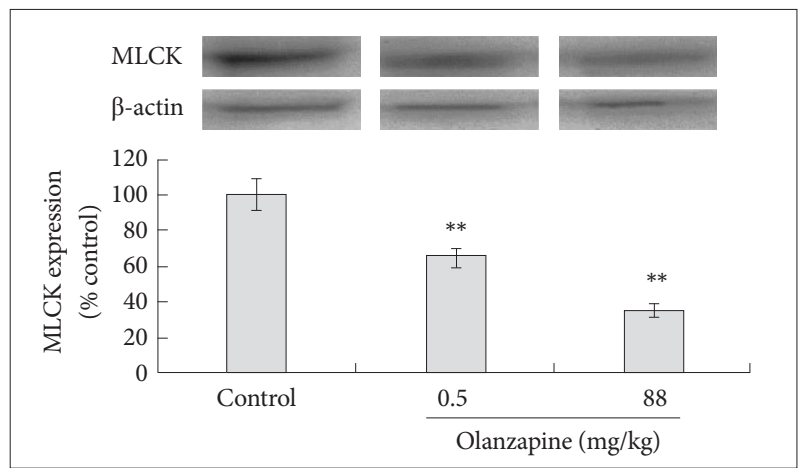

Figure 4. Effects of olanzapine on MLCK expression. All these data were expressed as means \pm standard divisions, $N=4$. The value in the control group was considered as $100 \%$. ${ }^{* *} p<0.01$. $\beta$-actin was used as the internal reference. MLCK: myosion light chain kinase.

\section{Effects of olanzapine on MLCK expression}

MLCK expression decreased significantly after olanzapine gavage (Figure 4). The MLCK level in the high dose group was $53.2 \%( \pm 2.9)$, which was significantly lower than the level in the control group $100.0( \pm 13.6) \%(\mathrm{p}<0.01)$.

\section{DISCUSSION}

Previous opinions suggested that olanzapine could antagonize peripheral $M_{2}$ and $M_{3}$ receptors to reduce gastric secretions, thus inhibiting the motility of gastrointestinal smooth muscles, and resulting in constipation. ${ }^{21}$ However, the antagonistic effects of olanzapine on $\mathrm{M}$ receptor are relatively low, thus there may be other mechanisms involved in the development of olanzapine induced constipation. Amount of previous studies demonstrated that $5-\mathrm{HT}_{3}$ receptors were mainly expressed in the intestinal and colonic smooth muscles, where olanzapine could effectively block the $5-\mathrm{HT}_{3}$ receptor. ${ }^{10-12}$ For this reason, olanzapine has ever been used in clinical practices for the treatment of IBS. ${ }^{22}$
In the present study, ex vivo experiments showed that olanzapine could inhibit dose-dependently the contraction of $e x$ vivo colonic smooth muscle in rats and reverse the activation of smooth muscles induced by 5-HT and ACh. It suggested that the inhibitory effect of olanzapine on rat colonic motility correlated with the antagonisms of 5-HT and ACh. The in vivo experiments in the present study showed that all rats treated with different doses of olanzapine developed constipation on day 30 after olanzapine gavage, which further suggested that olanzapine could antagonize certain peripheral receptors, probably 5-HT and ACh receptors, leading to constipation. SERT was distributed at the mucosal layer of the intestinal tract and the enteric nervous system. It could transport the 5-HT from the synaptic cleft to adjacent cells for further oxidative metabolism and thus regulate the conductive activity of serotonin nerves. ${ }^{23}$ However, these effects were associated with the expression of SERT on the membrane. ${ }^{24}$ The findings of the present study showed that the expression of SERT in the colonic smooth muscles increased one week after olanzapine gavage compared with control group, but significantly decreased on day 30 after olanzapine gavage. Increased expression of SERT could decrease 5-HT concentration in the synaptic clefts and thus inhibit colonic motility. The significant decrease of SERT could theoretically increase the transportation of 5-HT and thus improve the colonic motility, which could in turn decrease the risk of constipation. Although this theory was not directly supported by the present results, previous studies indicated that the increase of 5-HT in synaptic clefts increased sharply instead of gradually increasing,; ${ }^{25}$ and among the multiple 5-HT receptor family members, the 5- $\mathrm{HT}_{3}$ receptor is the only ligand-gated ion channel receptor and closely related to contraction of the smooth muscles and the secretion of gastric fluid, which makes it with high susceptible to desensitization. ${ }^{26}$ The significantly decreased expression of SERT in the rats received long-term olanzapine ga- 
vage could decrease the re-uptake of 5-HT. Therefore, large amounts of 5-HT would aggregate at the target site and thus induced desensitization of $5-\mathrm{HT}_{3}$ receptor, which in turn decreased the colonic motility and induced dysfunction. ${ }^{14,27,28}$ Based on the above theory, we indirectly speculated that olanzapine probably antagonize the $5-\mathrm{HT}_{3}$ receptor besides ACh receptor to cause constipation in rats. Some other studies also found that the expression of SERT in the intestinal mucosa of patients with chronic constipation was reduced, while constipation could not induce compensative changes in the 5-HT signaling pathway within the intestinal tract through feedback. ${ }^{28}$ These findings suggested that constipation and $5-\mathrm{HT}_{3}$ were essential prerequisites for each other's dysfunction, and they cooperate with each other to induce the development and progression of reduced colonic contraction. In addition, several other studies also found that $5-\mathrm{HT}_{3}$ receptor antagonist could increase the absorption of fluid in the jejunum. ${ }^{29}$ which could also be one of the mechanisms involved in the constipation risk increase caused by olanzapine.

MLCK is very important for gastrointestinal motility. Previous studies showed that a knock-out of the MLCK gene could reduce the gastrointestinal motility and the gastrointestinal tension in mice. ${ }^{16}$ The findings of the present study showed that olanzapine could significantly reduce expression of MLCK in the rat intestinal tract, suggesting that olanzapine could inhibit the expression of MLCK and thus reduce the contraction of smooth muscles. This in turn reduced the colonic motility and the forces on chyme. Previous studies showed that chlorpromazine, a CaM inhibitor, could widely influence the intracellular calcium-binding proteins and thus interfere the signal transductions mediated by $\mathrm{Ca}^{2+} \cdot{ }^{30}$ Inhibition of CaM could induce inactivation of MCLK and thus influence the contraction of intestinal smooth muscles. ${ }^{31}$ However, more studies would be needed to investigate whether the effects of olanzapine on the expression of MCLK are also involved in these procedures.

There are some limitations in our present study. Firstly, our study demonstrated that olanzapine inhibited 5-HT-induced colonic motility and constipation ex vivo. However, the involvement of ACh receptor couldn't be excluded, although olanzapine was a weaker antagonist at muscarinic receptor. ${ }^{5}$ Secondly, the present study couldn't directly concluded which 5-HT receptor subtypes was antagonized by olanzapine to cause abnormality of intestinal motility in rats, although previous evidence showed that the distribution of $5-\mathrm{HT}_{3}$ receptor in humans and rodents are mainly in gastrointestinal smooth muscle tissue, which could regulate the contraction of the smooth muscles and the secretion of gastric fluid. ${ }^{12}$ Thirdly, the protein level of CaM or the phosphorylation level of MLCK could well explain the possible involvement of $\mathrm{Ca} 2+-\mathrm{CaM}$ antagonistic action. Nevertheless, we only investigate the expression of MLCK with Western blot. Therefore, further study should focus on the unresolved above questions in the future.

In conclusion, we demonstrated that peripheral 5-HT receptor involved in the constipation induced by olanzapine. Furthermore, the effect of promoting intestinal motility of 5-HT was blocked by olanzapine, combined with the characteristics of the 5-HT receptor subtypes distribution in the gastrointestinal tract of rats and the pharmacological properties of olanzapine. Our results suggest serotonin antagonism and MLCK, besides M receptor, probably participated in the course of pathophysiology of constipation induced by olanzapine.

\section{Acknowledgments}

This study was funded National Natural Science Foundation of China (81230027, 81401127), Shanghai Natural Science Foundation (13ZR1460500), Key Laboratory of Psychotic Disorders (13dz2260500-14-K06), Animal special fund of the Science and Technology Commission of Shanghai (13140903400), Shanghai Changhai Hospital Foundation, and Postdoctoral Grant of Secondary Military Medical University. We would like to acknowledge the reviewers for their helpful comments on this paper.

\section{REFERENCES}

1. Prommer E. Olanzapine: palliative medicine update. Am J Hosp Palliat Care 2013;30:75-82.

2. Kelly DL, Richardson CM, Yu Y, Conley RR. Plasma concentrations of high-dose olanzapine in a double-blind crossover study. Hum Psychopharmacol 2006;21:393-398.

3. Chew ML, Mulsant BH, Pollock BG, Lehman ME, Greenspan A, Kirshner MA, et al. A model of anticholinergic activity of atypical antipsychotic medications. Schizophr Res 2006;88:63-72.

4. Rege S, Lafferty T. Life-threatening constipation associated with clozapine. Australas Psychiatry 2008;16:216-219.

5. Bymaster FP, Nelson DL, DeLapp NW, Falcone JF, Eckols K, Truex LL, et al. Antagonism by olanzapine of dopamine D1, serotonin2, muscarinic, histamine $\mathrm{H} 1$ and alpha 1-adrenergic receptors in vitro. Schizophr Res 1999;37:107-122.

6. Bymaster FP, Rasmussen K, Calligaro DO, Nelson DL, Nelapp NW, Wong DT, et al. In vitro and in vivo biochemistry of olanzapine: a novel, atypical antipsychotic drug. J Clin Psychiatry 1997;58(Suppl 10):28-36.

7. Bhana N, Foster RH, Olney R, Plosker GL. Olanzapine: an updated review of its use in the management of schizophrenia. Drugs 2001;61: 111-161.

8. Kim DY, Camilleri M. Serotonin: a mediator of the brain-gut connection. Am J Gastroenterol 2000;95:2698-2709.

9. Tamir H, Payette RF, Huang YL, Liu KP, Gershon MD. Human serotonectin: a blood glycoprotein that binds serotonin and is associated with platelets and white blood cells. J Cell Sci 1985;73:187-206.

10. Sikander A, Rana SV, Prasad KK. Role of serotonin in gastrointestinal motility and irritable bowel syndrome. Clin Chim Acta 2009;403:47-55.

11. Bymaster FP, Falcone JF, Bauzon D, Kennedy JS, Schenck K, Delapp NW, et al. Potent antagonism of 5-HT(3) and 5-HT(6) receptors by olanzapine. Eur J Pharmacol 2001;430:341-349.

12. Stasi C, Bellini M, Bassotti G, Blandizzi C, Milani S. Serotonin receptors and their role in the pathophysiology and therapy of irritable bowel syndrome. Tech Coloproctol 2014;18:613-621.

13. Kerckhoffs AP, Ter Linde JJ, Akkermans LM, Samsom M. Trypsinogen IV, serotonin transporter transcript levels and serotonin content are increased in small intestine of irritable bowel syndrome patients. Neurogastroenterol Motil 2008;20:900-907. 
14. Coates MD, Mahoney CR, Linden DR, Sampson JE, Chen J, Blaszyk $\mathrm{H}$, et al. Molecular defects in mucosal serotonin content and decreased serotonin reuptake transporter in ulcerative colitis and irritable bowel syndrome. Gastroenterology 2004;126:1657-1664.

15. Costedio MM, Hyman N, Mawe GM. Serotonin and its role in colonic function and in gastrointestinal disorders. Dis Colon Rectum 2007;50: 376-388.

16. He WQ, Peng YJ, Zhang WC, Lv N, Tang J, Chen C, et al. Myosin light chain kinase is central to smooth muscle contraction and required for gastrointestinal motility in mice. Gastroenterology 2008;135:610-620.

17. Murthy KS. Signaling for contraction and relaxation in smooth muscle of the gut. Annu Rev Physiol 2006;68:345-374.

18. Hu W, Feng P. Myosin light chain kinase is involved in the mechanism of gastrointestinal dysfunction in diabetic rats. Dig Dis Sci 2012;57: 1197-1202.

19. Umer A, Lugowska H, Sein-Anand J, Rekowski P, Ruczynski J, Petrusewicz J, et al. The contractile effects of several substituted short analogues of porcine galanin in isolated rat jejunal and colonic smooth muscle strips. Pharmacol Res 2005;52:283-289.

20. Xiong YJ, Chen DP, Lv BC, Liu FF, Wang L, Lin Y. The characteristics of genistin-induced inhibitory effects on intestinal motility. Arch Pharm Res 2013;36:345-352.

21. Bymaster FP, Felder CC, Tzavara E, Nomikos GG, Calligaro DO, Mckinzie DL. Muscarinic mechanisms of antipsychotic atypicality. Prog Neuropsychopharmacol Biol Psychiatry 2003;27:1125-1143.

22. Farthing MJ. Irritable bowel syndrome: new pharmaceutical approaches to treatment. Baillieres Best Pract Res Clin Gastroenterol 1999;13:461471.

23. Wade PR, Chen J, Jaffe B, Kassem IS, Blakely RD, Gershon MD. Local- ization and function of a 5-HT transporter in crypt epithelia of the gastrointestinal tract. J Neurosci 1996;16:2352-2364.

24. Spiller R. Serotonin and GI clinical disorders. Neuropharmacology 2008;55:1072-1080

25. Atkinson W, Lockhart S, Whorwell PJ, Keevil B, Houghton LA. Altered 5 -hydroxytryptamine signaling in patients with constipation- and diarrhea-predominant irritable bowel syndrome. Gastroenterology 2006; 130:34-43.

26. Derkach V, Surprenant A, North RA. 5-HT3 receptors are membrane ion channels. Nature 1989;339:706-709.

27. Guarino M, Cheng L, Cicala M, Ripetti V, Biancani P, Behar J. Progesterone receptors and serotonin levels in colon epithelial cells from females with slow transit constipation. Neurogastroenterol Motil 2011;23:575e210.

28. Costedio MM, Coates MD, Brooks EM, Glass LM, Ganguly EK, Blaszyk $\mathrm{H}$, et al. Mucosal serotonin signaling is altered in chronic constipation but not in opiate-induced constipation. Am J Gastroenterol 2010;105: 1173-1180.

29. Gustafsen J, Lendorf A, Raskov H, Boesby S. Ketanserin versus placebo in carcinoid syndrome. A clinical controlled trial. Scand J Gastroenterol 1986;21:816-818.

30. Kawamura H, Arai M, Togari A. Inhibitory effect of chlorpromazine on RANKL-induced osteoclastogenesis in mouse bone marrow cells. J Pharmacol Sci 2011;117:54-62.

31. Gonzalez-Andrade M, Mata R, Madariaga-Mazon A, Rodriguez-Sotres $\mathrm{R}$, Del PL, Sosa-Peinado A. Importance of the interaction protein-protein of the CaM-PDE1A and CaM-MLCK complexes in the development of new anti-CaM drugs. J Mol Recognit 2013;26:165-174. 